\title{
A Novel Self-Powered Smart Current Sensor for Power Equipment
}

\author{
Jie Ren ${ }^{1}$, Yong Sun ${ }^{1}$, Shuo Zhang ${ }^{2}$, Shidong Zhang ${ }^{1}$, Yadong $\mathrm{Liu}^{3}$, Kejun $\mathrm{Li}^{3}$, Xiucheng Jiang ${ }^{3}$ \\ ${ }^{I}$ Electric Power Research Institute of Shandong Electric Power Company, \\ No. 2000 Wangyue Road, Shizhong District, Jinan, China \\ ${ }^{2}$ Electric Power Research Institute of Jibei Electric Power Company, \\ No. 1 Dizangannan Road, Xicheng District, Beijing, China \\ ${ }^{3}$ Institute of Intelligent Power Transmission and Distribution, Shanghai Jiao Tong University, \\ No. 800 Dongchuan Road, Minhang District, Shanghai, China \\ lyd@sjtu.edu.cn
}

\begin{abstract}
Current measurement is one of the most important work in online monitoring of the electric system. Self-powered and intelligence are key areas of the current measuring sensor. In this paper, a self-powered current measuring sensor realizing measurement and power supply synchronously was designed. The different functions of current transformer were integrated and the mathematical relationship between the line current and the CT secondary side output was deduced. The model for current measurement based on different signals before or after the rectifier bridge was constructed. The overall design of the current measuring equipment was given. Finally, the accuracy of different measuring models was verified by experiments and test results under load changes were analysed.
\end{abstract}

Index Terms-Rogowski-coil; Self-powered; Current transformer; High current sensor.

\section{INTRODUCTION}

Recently, the development of industries requires more reliable power supplies which have made the transmission and distribution networks more massive. Due to its extensive distribution and complicated running environment, complete state analysis and fault protection is very important. Online condition monitoring is the guarantee to achieve the requirements [1].

The new technologies of smart grid such as dynamic line rating [2] and situational awareness [3] need to obtain the panoramic wide-area line operating parameters, which are based on a widely distributed condition monitoring system. As an important part of condition monitoring, current measurement of line can reflect running state of power grid and indicate many line failures intuitively [4]. Therefore, current measurement is the core part of condition monitoring technology. With the expansion of the network scale, it is very important to realize the optimal configuration of the current measurement devices with limited cost to improve the observability of the system as much as possible. The

Manuscript received 18 April, 2018; accepted 19 November, 2018

This research was funded by a Grant (No. 51307109) from the National Natural Science Foundation of China and a Grant (No. 13dz1201302) from Scientific Research Plan Project of Shanghai Science and Technology Commission. development of distribution puts forward new requirements for the current measurement devices: Firstly, the circuit and structure design of the measurement module should be simplified. Under the premise of required precision, the factors such as economy, reliability, observability and robustness should be taken into account. Secondly, the power supply module supporting the device should meet the needs of miniaturization and low cost, and ensure continuous power supply in a complex environment.

Many types of research on the sensing theory of the current measurement sensor have been reported [5]-[7]. Common non-contact current measurement methods in the electric power system are AC current transformer, Rogowski coil [8], Hall current sensor [9], fluxgate and optical current sensor [10], etc. Among which the current transformer (CT) is a widely used solution. The CT is clamped onto the line, the primary side large current is converted into the secondary side low current based on the electromagnetic induction principle, finally the current is measured through the conditioning circuit. Meanwhile, there are many mature studies [11]-[13] on power supply technology. Compared with the laser power supply [14] and the solar power supply [15], the induction power supply is more suitable for this situation. Energy is acquired by the coils of the transformer and the power supply can be continuously maintained to ensure uninterrupted operation of the equipment. We find that most of the previous researches isolated the two aspects of current measurement and power supply. The design of the measurement circuit and the energy acquisition circuit of the specific device are also separated. However, the CT is not only the core component of the current measurement, but also can be used as a part of the power supply. The difference is the realization of their respective functions through different follow-up circuit designs. Therefore, this paper explored a solution to integrate the transformer for energy harvesting and the transformer for measuring, apply existing energy harvesting magnetic core to current measurement, thus making measurement and power supply synchronously. And then a novel self-powered smart current sensor for power equipment was designed.

Such a self-powered design can offer energies through 
lines directly, thus enabling it to achieve continuous energy supply in complex environment. The equipment has a tight structure and simple capsulation [16], which simplifies the supply circuit design significantly and meets the requirements of small size and low cost. Moreover, the power supply circuit and transmission lines are kept insulated, which improves safety and stability. Due to the large number of transmission and distribution lines, the wide application of the smart current sensor will greatly reduce costs in order to achieve distributed measurement. In theory, the smart current sensor provides a new solution for the measurement of current in power lines, which enriches the state of existing knowledge. In application, the current measurement accuracy of the device is $2.5 \%$, which can be applied to a variety of practical situations.

The mathematical relationships between the primary side current, the secondary side voltage and current of the transformer were deduced based on the experimental circuit of the power supply. Therefore, the measurable goal could be realized by calculating the primary side current from the secondary side voltage and current components. Generally, there is a rectification unit at the secondary side of the transformer in order to realize the power supply of post-stage circuit. Calculations of the primary side current based on the voltage and current before and after the rectifier bridge were discussed, respectively. The overall flowchart of the current measuring sensor was introduced. The design of the current measuring sensor was put forward, which comprises an energy supply module and measurement module. Finally, the measurement validity of the proposed equipment was verified by an experiment and test results under load changes under connection of the power supply module were analysed.

The designed self-powered current measuring sensor can simplify the design of online monitoring and fault positioning device significantly, optimize volume and weight of the device, realize low-power running, and make full use of the transducer. Current measurement can detect low current and surge current throughout the energy harvesting process, and prevent supply shortage caused by great current changes or overvoltage breakdown of the power grid. The self-powered function also can offer an adequate power supply guarantee for current measurement and thereby improves the accuracy of online monitoring.

\section{Principle of Current Measuring TechniQue}

The basic working principle of the energy harvesting device [17] is shown in Fig. 1. The primary side wire runs through the magnetic core and the current in the wire is $\dot{I}_{1}$. The secondary side current is $\dot{I}_{1}$. The number of turns of the primary coil and the secondary coil are $N_{l}(=1)$ and $N_{2}$. Suppose the transformer working in the linear region.

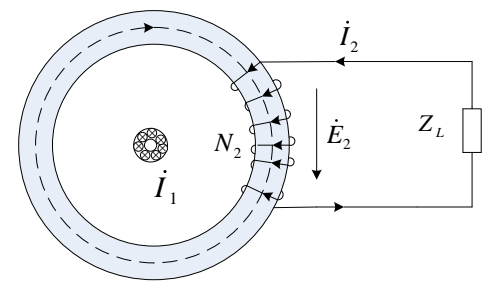

Fig. 1. Working principle of the energy harvesting device.
According to the basic theory of electromechanics [18], the secondary side voltage of the magnetic core $\left(E_{2}\right)$ could be expressed as

$$
E_{2}=\sqrt{2} \pi f N_{2} \Phi_{m}
$$

where $\Phi_{m}=B_{m} S, \Phi_{m}$ is the maximum main flux, and $f$ is the power frequency. Let $S$ be the net sectional area of the magnetic core. Combined with the Ampere circuit law: $H_{m} l=\sqrt{2} N_{1} I_{\mu}, E_{2}$ can be represented as

$$
E_{2}=\frac{2 \pi f N_{2} \mu N_{1} I_{\mu} S}{l}
$$

where $I_{\mu}$ is magnetizing current, $l$ is the average length of a magnetic path and $\mu$ is magnetic permeability.

According to the equilibrium equation of magnetomotive force of the transformer, if the core loss current is neglected, there's

$$
\dot{I}_{1} \dot{N}_{1}+\dot{I}_{2} \dot{N}_{2}=\dot{I}_{\mu} \dot{N}_{\mu}
$$

Substitute (3) into (2), and the relationships between the secondary side voltage, the primary side current and the secondary side current could be known

$$
I_{1}=\frac{E_{2} l}{2 \pi f N_{2} \mu S N_{1}}-\frac{N_{2} I_{2}}{N_{1}},
$$

where $I_{l}$ is the power frequency component, and the secondary side voltage $E_{2}$ and the secondary side current $I_{2}$ contain higher harmonics $(>3)$. Therefore, it can conclude that $E_{2}$ and $I_{2}$ have same third harmonic phase position. Then, the primary side current could be calculated by measuring the power frequency component of the secondary side voltage and current, thus realizing the goal of current measurement.

Generally, there's a rectification filtration module on the secondary side of the transformer for the sake of power supply to post-stage circuits. The voltage and current waveforms before and after the rectifying circuit are different, but have a certain mathematical relationship. In the actual device, the voltage and current before the rectifier bridge is the secondary side voltage $E_{2}$ and current $I_{2}$ in (4). Therefore, measuring results could be gained directly by calculating the power frequency component. The relationship between the voltage FFT after the rectifier bridge and the voltage FFT before the rectifier bridge shall be analysed firstly and then the primary side current could be calculated.

The typical voltage waveform before and after the rectifier bridge is shown in Fig. 2.

It can be seen in Fig. 2 that the voltage waveform after the rectifier bridge $\left(U^{\prime}\right)$ is the superposition of a DC component $U_{d c}$ and an approximate sawtooth wave $U_{b}$, which has a corresponding mathematical relationship with the waveform before the rectifier bridge $(U)$. $U_{d c}$ is corresponding to the square wave before the rectifier bridge $U_{s q}$ with the same amplitude, while $U_{b}$ is corresponding to the waveform before the rectifier bridge folded along the $\mathrm{x}$-axis $\left(U_{a}\right)$. The mathematical relationships between the voltage components 
are: $U=U_{s q}+U_{a}$ and $U^{\prime}=U_{d c}+U_{b}$. The diagrams of $U_{a}$ and $U_{b}$ are shown in Fig. 3 .
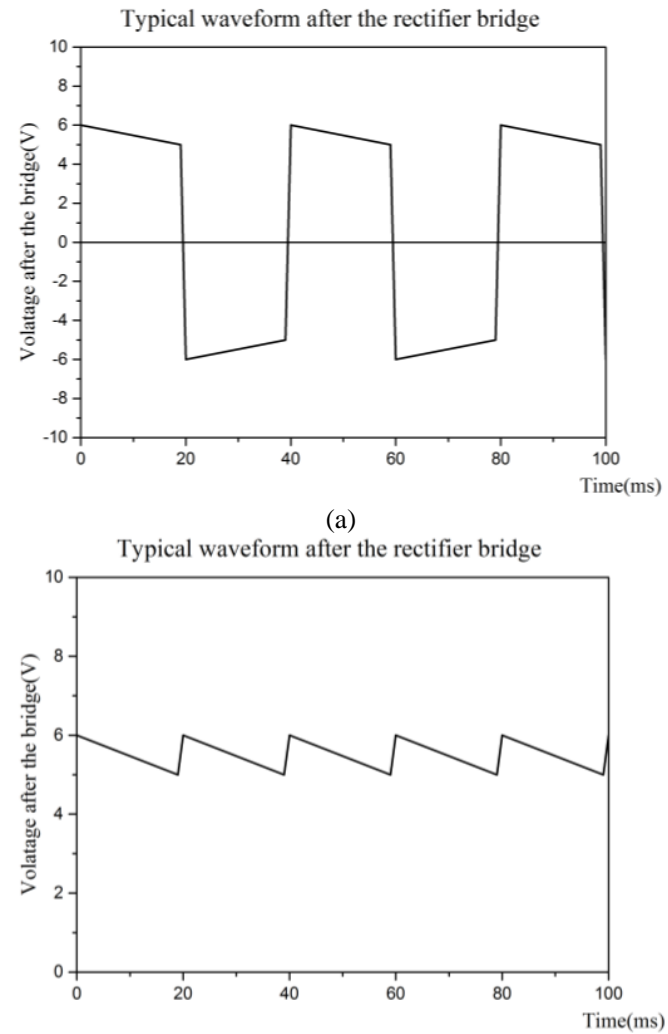

(b)

Fig. 2. Typical waveform: a) typical waveform before the rectifier bridge; b) typical waveform after the rectifier bridge.

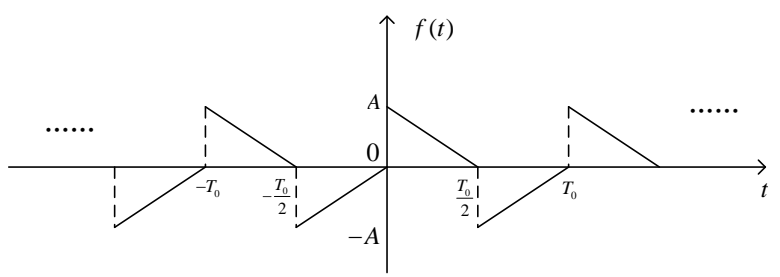

(a)

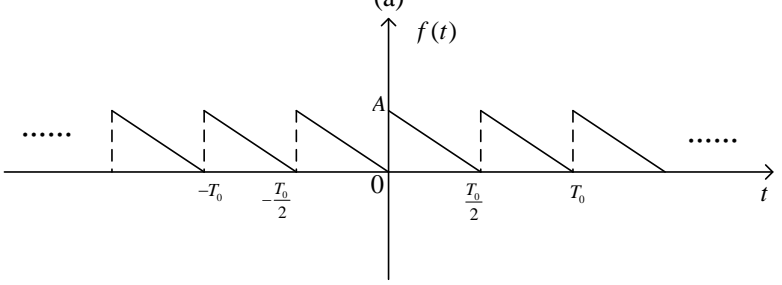

(b)

Fig. 3. Correspondences of waveforms before and after the rectifier bridge: a) voltage waveform $U_{a}$; b) voltage waveform $U_{b}$.

It assumes that $\mathrm{A}=2$ for the convenience of calculation. The Fourier expansion calculation of the $U_{a}$ waveform is

$$
\begin{gathered}
U_{a}(t)=\frac{8}{\pi^{2}}\left(\cos \omega_{0} t+\frac{1}{9} \cos 3 \omega_{0} t+\right. \\
\left.+\frac{1}{25} \cos 5 \omega_{0} t+\cdots+\frac{1}{n^{2}} \cos n \omega_{0} t\right)+ \\
+\frac{4}{\pi}\left(\sin \omega_{0} t+\frac{1}{3} \sin 3 \omega_{0} t+\frac{1}{5} \sin 5 \omega_{0} t+\cdots+\frac{1}{n} \sin n \omega_{0} t\right)
\end{gathered}
$$

where $\omega_{0}$ is the fundamental frequency $(50 \mathrm{~Hz})$. The amplitude of $50 \mathrm{~Hz}$ component is 1.5094 .
The Fourier expansion calculation of the $U_{b}$ waveform is

$$
\begin{gathered}
U_{b}(t)=1+\frac{2}{\pi}\left(\sin 2 \omega_{0} t+\frac{1}{2} \sin 4 \omega_{0} t+\right. \\
\left.+\frac{1}{3} \sin 6 \omega_{0} t+\cdots+\frac{1}{n} \sin 2 n \omega_{0} t\right) .
\end{gathered}
$$

The amplitude of $100 \mathrm{~Hz}$ component is 0.6366 .

According to the previous analysis, the calculation of current measurement only needs to obtain the $50 \mathrm{~Hz}$ component of the secondary side voltage $E_{2}$ which is equalled with the voltage $U$. This component consists of two parts: the $50 \mathrm{~Hz}$ component of the square wave $U_{s q}$ and the sawtooth wave $U_{a}$.

The calculated results show that the $50 \mathrm{~Hz}$ component of $U_{a}$ is 2.37 times that of $100 \mathrm{~Hz}$ component of $U_{b}$. Considering the FFT relationship between the square wave and DC component, the calculation formula of the final FFT amplitude is

$$
F_{50}=\frac{4 f_{0}}{\pi}+2.37 f_{100}
$$

where $F_{50}$ is the $50 \mathrm{~Hz}$ component of voltage before the rectifier bridge, $f_{0}$ is the $\mathrm{DC}$ component after the rectifier bridge, and $f_{100}$ is the $100 \mathrm{~Hz}$ component after the rectifier bridge.

According to (7), the calculated $50 \mathrm{~Hz}$ component is used as the secondary side voltage during operation, while the secondary side current uses the current before the rectifier bridge. Substitute them into (4), and then

$$
I_{1}=\frac{\left(\frac{4 E_{0 h z}^{\prime}}{\pi}+2.37 E_{100 h z}^{\prime}\right) l}{2 \pi f N_{2} \mu S N_{1}}-\frac{N_{2} I_{2}}{N_{1}} .
$$

The equation (4) calculates the primary side current by using the voltage and current signal before the rectifier bridge, whereas (8) calculates the primary side current with the voltage signal after the rectifier bridge and current signal before the rectifier bridge. The current sensing device can establish two different current measuring models according to these two calculation methods.

\section{Design of CURRENT MEASURING SENSOR}

The current measuring sensor measures the primary side current by the above algorithm based on the intrinsic parameters of the transformer and the secondary side voltage and current. The system structure of the designed sensor is shown in Fig. 4. The sensor is hung on the transmission line and the transmission line passes through the magnetic core which acquires energy from current in the transmission line through electromagnetic induction and supplies power to the measuring circuit through the energy supply circuit. The measuring circuit collects voltage and current waveform data at several nodes in the energy supply circuit, calculates the primary side current through the signal processing circuit, and finally store or communicate the final results to realize the further function. For the entire device, the load refers to 
the power consumed by the measuring part. As long as the energy supply part can supply power normally, it can complete the acquisition and realize the measurement. The above process is carried out at the same time thus achieving the synchronization of power supply and measurement.

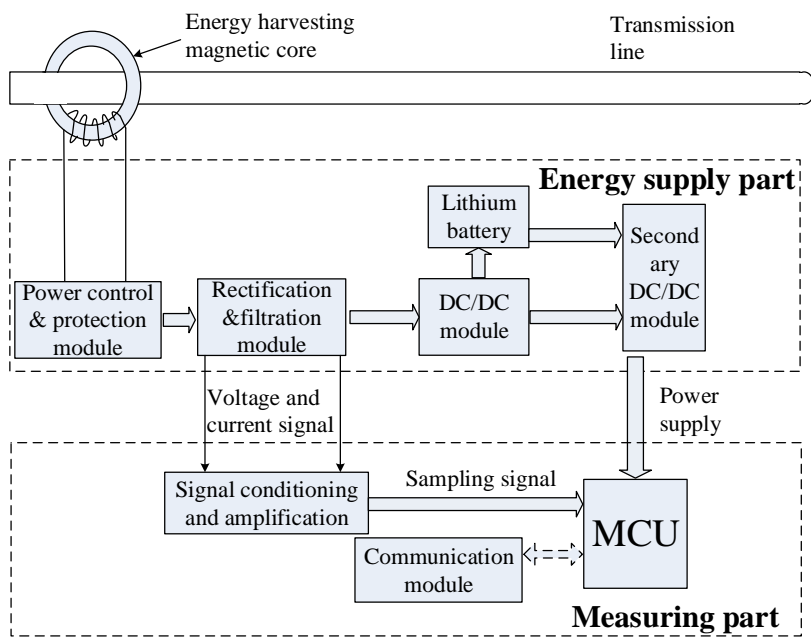

Fig. 4. System structure of the designed current measuring sensor.

The energy supply part is composed of power control and protection module, rectification filtration module and DC-DC module. A lithium battery was designed as the standby power supply to ensure the continuous running of the sensor. Moreover, a protective circuit was designed to prevent damage to the sensor caused by sharp current growth at the breakdown.

The measuring part includes the microprogrammed control unit (MCU), signal conditioning module and communication module. The MCU is for synchronous collection, the operation and storage of voltage and current signals. The signal conditioning module collects the secondary side voltage and current of the transformer. The signal collection could be accomplished at any position before and after the rectifier bridge of the energy supply circuit. The communication module is responsible for communication among different phases or communication between remote monitoring primary stations.

The application of the current measuring sensor has to consider the current range of the transmission lines. With respect to the electromagnetic core, it may not produce adequate voltage under low current of the transmission line and will consume excessive energies to ensure supply of stable DC voltage under high current of the transmission line. Due to the dynamic wide range of current of the transmission line, this design involves a lithium battery as the standby power supplies and an energy storing device to cope with situations of low current. Additionally, it has overvoltage protection, power control module to handle situations of high current and surge current of the transmission line.

For the measuring module, the establishment of measuring algorithm requires the energy harvesting transformer working in the linear region in order to avoid influences brought by loss and magnetic saturation as much as possible. In other words, under the condition of power frequency, the primary current of the transformer has a linear relationship with the output voltage and output current, which requires a special design for the transformer. This design adds an air gap at the point of contact of the energy harvesting magnetic core and expands the linear region of the magnetic core, which makes the secondary output of the transformer cover the maximum current range. The size of the energy harvesting magnetic core shall be determined with comprehensive consideration to the size of transmission lines and power standard. Since the sensor will hang on the overhead line for a long time, the overall weight of the sensor shall be controlled within $1.5 \mathrm{~kg}$ and the magnetic core weight is designed smaller than $500 \mathrm{~g}$. The line current is larger than 20 A under normal conditions. The load circuit applies ultralow power consumption design, about $300 \mathrm{~mW}$ to the lowest. Therefore, $300 \mathrm{~mW} / 20 \mathrm{~A} / 500 \mathrm{~g}$ power density of the energy harvesting magnetic core can ensure stable power supply of the device. The power estimation formula of the power supply module is [19]:

$$
\begin{gathered}
E_{2}=2 \pi f N_{2}^{\prime} \mu S \frac{I_{\mu}}{l}>V_{\min }, \\
P=V_{\min } \frac{\sqrt{I_{1}^{2}-\left(\frac{V_{\min } l}{2 \pi f N_{2}^{\prime} \mu S}\right)^{2}}}{N_{2}^{\prime}}>P_{\min },
\end{gathered}
$$

where $\mu$ is magnetic conductivity of the magnetic core, $I_{\mu}$ is exciting current, $S$ is sectional area of the magnetic core, $l$ is length of a magnetic path that could be calculated from size of the magnetic core, $I_{1}$ is the primary side current (20 A), $N_{2}$ ' is number of turns, $V_{\min }$ is the lowest working voltage of post-stage voltage stabilization chip, and $P_{\min }$ is the lowest output power, which is determined $0.55 \mathrm{~W}$ with considerations to output efficiency and power consumption requirements of the magnetic core.

According to (9), the cold-rolled silicon steel sheet 30Q110 was chosen as the energy harvesting magnetic core. Inner diameter, outer diameter, height and number of turns of the magnetic core were set $55 \mathrm{~mm}, 75 \mathrm{~mm}, 30 \mathrm{~mm}$ and 200 $\mathrm{mm}$, which could meet requirements of the device.

Performance indexes of the designed current measuring sensor are:

The designed current measuring sensor was applied to middle and high-voltage transmission lines. The voltage grade was $110 \mathrm{kV} / 220 \mathrm{kV}$ and the normal current range was controlled within $1000 \mathrm{~A}$. Combining limitations of the measurement model, the current measuring range was 40 A 1000 A. The measuring sensor used ultralow power consumption design and the power consumption under normal operation was as low as $300 \mathrm{~mW}$. When the line current is higher than $20 \mathrm{~A}$, the self-powered module can supply power to the whole system. Combined with actual conditions of the transmission network and related rule of the line safety, main technical parameters of the designed self-powered current measuring sensor are, current measurement range: 40 A 1000 A; measuring accuracy: $2.5 \%$; average power consumption < $300 \mathrm{~mW}$; sensor weight: $1.5 \mathrm{~kg}$. The applicable line diameter was 50 $\mathrm{mm}^{2} \sim 240 \mathrm{~mm}^{2}$ and the power supply mode was induction power supply + lithium battery. The mode of time adjustment used GPS/Beidou and the communication mode adopted Zigbee/GPRS. The working current was 20 A 1000 A. 
The overall prototyping test of the current measuring sensor is shown in Fig. 5.

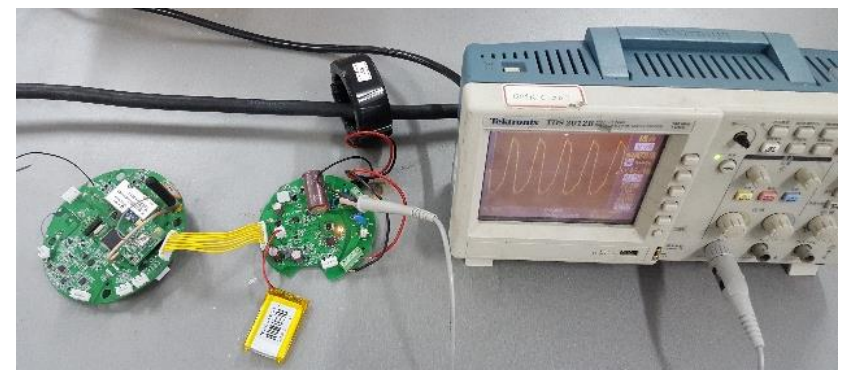

Fig. 5. Prototyping test of current measuring sensor.

Compared with the existing current measuring device, the design of this paper has higher superiority. For a complete set of equipment, the cost is less than $\$ 300$, with a precision of $2.5 \%$; and the cost of the other existing current measuring equipment is over $\$ 700$, or even more than $\$ 1000$, with a precision range of $1 \%$ to $4 \%$. Compared with the existing current sensors, the self-powered smart current sensor can meet the basic requirements in precision, but the cost is reduced a lot as well as the weight and volume, which provides the conditions for the realization of distribution and miniaturization.

\section{EXPERIMENTAL VERIFICATION}

To verify the accuracy of measurement principle, an experiment was designed to test the performance of core parts of the sensor. The current source generates standard sinusoidal signals with different amplitudes to simulate different line currents. Firstly, the harmonic relationship between the secondary side voltage and the current was verified. Next, the primary side current was calculated according to signals before and after the rectifier bridge. Finally, influences of load changes on test results were analysed.

Experimental apparatus includes energy harvesting, three-phase power source CL303, several resistors, rectifier bridge KBL406, DC-DC LM78H05, $470 \mathrm{uF}$ capacitor and oscilloscope. Several parameters are shown in the following Table I.

TABLE I. SEVERAL PARAMETERS

\begin{tabular}{|c|c|}
\hline Module & Parameters \\
\hline $\begin{array}{c}\text { The cold-rolled 30Q110 magnetic } \\
\text { core }\end{array}$ & $\begin{array}{c}\text { Inner diameter } 55 \mathrm{~mm} \text {, outer } \\
\text { diameter 75 mm, height } 30 \mathrm{~mm}, \\
\text { number of turns } 200\end{array}$ \\
\hline Rectifier bridge KBL406 & $\begin{array}{c}\text { Reverse voltage 420 V, max } \\
\text { forward current 4A, forward } \\
\text { voltage drop 1.1 V }\end{array}$ \\
\hline DC-DC LM78H05 & $\begin{array}{c}\text { Input voltage range 9 V-72 V, max } \\
\text { output current } 500 \mathrm{~mA}\end{array}$ \\
\hline
\end{tabular}

The experimental circuit is shown in Fig. 6.

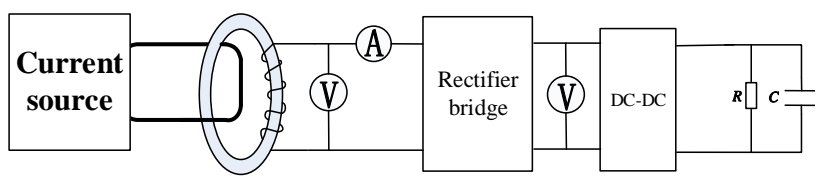

Fig. 6. Experimental circuit.

\section{A. Verification of the Harmonic Phase Relationship of the Secondary Side}

The typical waveforms before and after the rectifier bridge were measured and recorded in the above experimental circuit (Fig. 7).

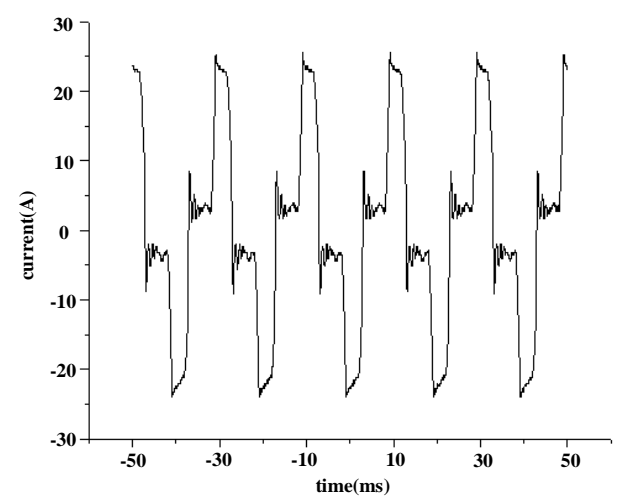

(a)
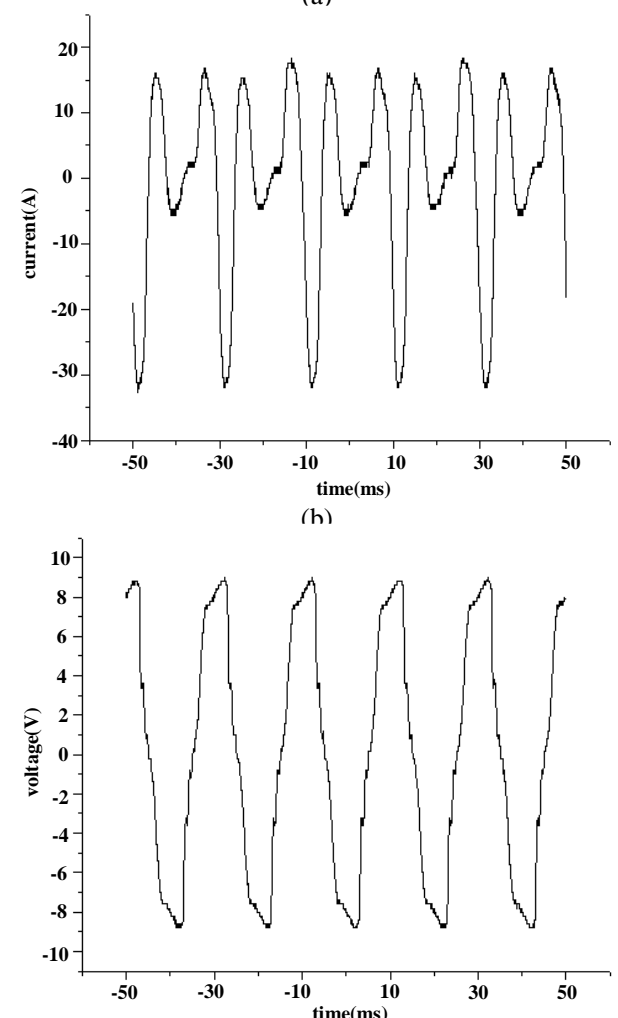

(c)

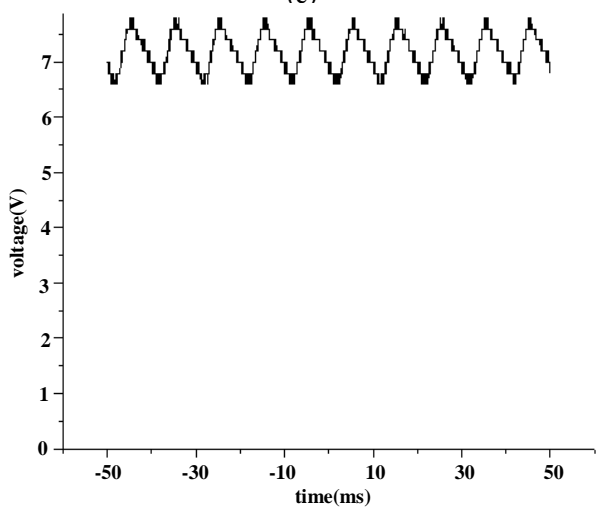

(d)

Fig. 7. Typical waveforms before and after the rectifier bridge: a) current waveform before the rectifier bridge; b) current waveform after the rectifier bridge; c) voltage waveform before the rectifier bridge; d) voltage waveform after the rectifier bridge. 
Amplitudes and phase angles of each harmonic were gained through fast Fourier transform of the above waveforms. Experimental voltage and current before the rectifier bridge were used as the secondary side voltage $E_{2}$ and the secondary side current $I_{2}$. Phase positions of the third harmonic were compared (Table II).

TABLE II. PHASE POSITIONS OF THREE HARMONICS.

\begin{tabular}{|c|c|c|}
\hline $\mathbf{I}_{\mathbf{1}}(\mathbf{A})$ & $\begin{array}{c}\text { Phase angle of the third } \\
\text { harmonic of } \boldsymbol{E}_{\boldsymbol{2}}\end{array}$ & $\begin{array}{c}\text { Phase angle of the third } \\
\text { harmonic of } \boldsymbol{I}_{\boldsymbol{2}}\end{array}$ \\
\hline 200 & 36.65 & 38.57 \\
\hline 250 & 40.43 & 41.28 \\
\hline 300 & 36.16 & 34.34 \\
\hline 350 & 8.17 & 8.62 \\
\hline 400 & 5.54 & 3.22 \\
\hline 450 & 10.39 & 9.39 \\
\hline 500 & 16.72 & 14.56 \\
\hline
\end{tabular}

In Table II, the FFT analysis concludes basically same phase position of the third harmonic of $E_{2}$ and $I_{2}$, which agrees with theoretical calculation.

\section{B. Calculation and Test Based on Signal Before the Rectifier Bridge}

Voltage and current before the rectifier bridge were used as the secondary side voltage and current. Therefore, the primary side current could be calculated by the theoretical formula directly

$$
I_{1}=\frac{E_{2} l}{2 \pi f N_{2} \mu S N_{1}}-\frac{N_{2} I_{2}}{N_{1}} .
$$

A $500 \Omega$ load was connected after the rectifier bridge. Bring in the measurement data and the calculated results are shown in Table III.

TABLE III. CALCULATED PRIMARY SIDE CURRENT BASED ON VOLTAGE AND CURRENT BEFORE THE RECTIFIER BRIDGE (UNIT: A).

\begin{tabular}{|c|c|c|c|}
\hline $\begin{array}{c}\text { Actual } \\
\text { value }\end{array}$ & Calculated value & Fitted value & $\begin{array}{c}\text { Error (error/total } \\
\text { range) }\end{array}$ \\
\hline 50 & 60.2258 & 58.5034 & $1.70 \%$ \\
\hline 100 & 106.2249 & 107.4502 & $1.49 \%$ \\
\hline 150 & 156.3444 & 156.3970 & $1.28 \%$ \\
\hline 200 & 203.3174 & 205.3438 & $1.07 \%$ \\
\hline 250 & 252.5261 & 254.2906 & $0.86 \%$ \\
\hline 300 & 304.0149 & 303.2374 & $0.65 \%$ \\
\hline 350 & 355.3479 & 352.1842 & $0.44 \%$ \\
\hline 400 & 403.4652 & 401.1310 & $0.23 \%$ \\
\hline 450 & 448.4594 & 450.0778 & $0.02 \%$ \\
\hline 500 & 497.7144 & 499.0246 & $0.20 \%$ \\
\hline
\end{tabular}

For most measuring devices, a measuring range is set before work, and the range of this experimental setup is $500 \mathrm{~A}$. In the table, the actual value represents the constant current output of the current source; the calculated value represents the current value calculated by (10). In order to reduce the deviation caused by single measurement, linear fitting of data is carried out. The empirical expression and the correlation factor are:

$$
\left\{\begin{array}{l}
y=0.9789 x+9.5566 \\
R^{2}=0.9998
\end{array}\right.
$$

This formula represents the measured value y (i.e., the fitted value) obtained by the device when the actual current is $\mathrm{x}$. The error in the table represents the difference between the fitted value and the actual value, and the basis for estimating the errors is the total range (500 A). In Fig. 8, the ideal curve represents the ideal result in the absence of error, and serves as a contrast; the measured curve represents the measurement performance of this algorithm.

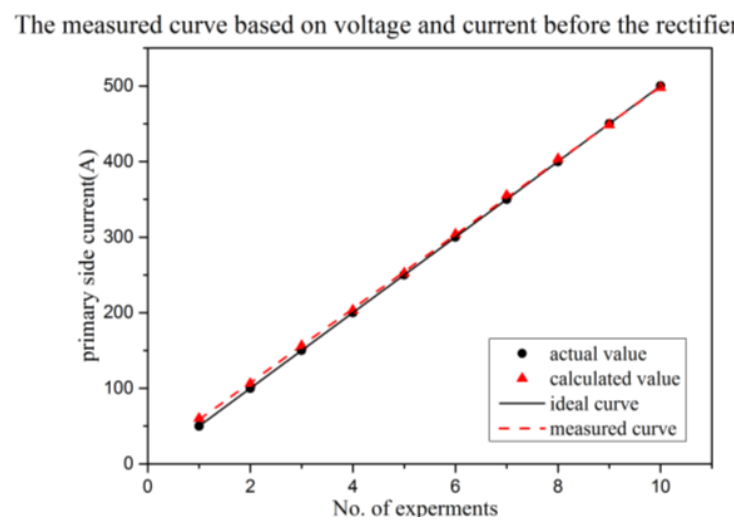

Fig. 8. The measured curve based on data before the rectifier bridge.

Table III and Fig. 8 reveal that the calculated primary side current based on the voltage and current before the rectifier bridge basically agree with the actual value. The error is within the allowable range, indicating that the theoretical formula is accurate.

\section{Calculation and Test Based on Signal after the Rectifier Bridge}

Voltage values before and after the rectifier bridge were measured in the experiment and then used for FFT analysis. Firstly, the actual value of the power frequency component of the voltage before the rectifier bridge was calculated. Next, DC component and the $100 \mathrm{~Hz}$ component of the voltage after the rectifier bridge were used in the calculation. Results were compared (Table IV).

TABLE IV. ACTUAL VALUE AND CALCULATED VALUE OF POWER FREQUENCY COMPONENT OF THE VOLTAGE BEFORE THE BRIDGE (UNIT: V).

\begin{tabular}{|c|c|c|c|c|}
\hline & \multicolumn{2}{|c|}{$50 \Omega$ load } & \multicolumn{2}{c|}{$100 \Omega$ load } \\
\hline$I_{1}$ & $\begin{array}{c}\text { Actual } \\
\text { value }\end{array}$ & $\begin{array}{c}\text { Calculated } \\
\text { value }\end{array}$ & $\begin{array}{c}\text { Actual } \\
\text { value }\end{array}$ & $\begin{array}{c}\text { Calculated } \\
\text { value }\end{array}$ \\
\hline $250 \mathrm{~A}$ & 1.7164 & 1.5329 & 2.3171 & 2.1973 \\
\hline $300 \mathrm{~A}$ & 2.0549 & 1.9574 & 2.7830 & 2.6103 \\
\hline $350 \mathrm{~A}$ & 2.3755 & 2.3065 & 3.2384 & 3.1246 \\
\hline $400 \mathrm{~A}$ & 2.7121 & 2.7025 & 3.6575 & 3.6396 \\
\hline $450 \mathrm{~A}$ & 3.0407 & 3.1261 & 4.0559 & 4.1099 \\
\hline $500 \mathrm{~A}$ & 3.3602 & 3.5380 & 4.4774 & 4.6461 \\
\hline
\end{tabular}

Results under different loading conditions after the rectifier bridge are listed in Table IV. The calculated power frequency component before the rectifier bridge, according to the above formula, has a small error with actual results which are directly measured. The theoretically calculated results agree with actual expectation.

The power frequency component of voltage before the rectifier bridge was calculated from the non-power frequency component of voltage after the rectifier bridge, which was 
used as the secondary side voltage in the operation. The secondary side current used the current before the rectifier bridge. According to the theoretical formula, the collected data were computed

$$
I_{1}=\frac{\left(\frac{4 E_{0 h z}^{\prime}}{\pi}+2.37 E_{100 h z}^{\prime}\right) l}{2 \pi f N_{2} \mu S N_{1}}-\frac{N_{2} I_{2}}{N_{1}} .
$$

Calculated primary side currents under $500 \Omega$ load after the rectifier bridge are presented in Table $\mathrm{V}$.

TABLE V. CALCULATED PRIMARY SIDE CURRENT BASED ON VOLTAGE AFTER THE RECTIFIER BRIDGE (UNIT: A).

\begin{tabular}{|c|c|c|c|}
\hline $\begin{array}{c}\text { Actual } \\
\text { value }\end{array}$ & $\begin{array}{c}\text { Calculated } \\
\text { value }\end{array}$ & $\begin{array}{c}\text { Fitted } \\
\text { value }\end{array}$ & $\begin{array}{c}\text { Error (error/total } \\
\text { range) }\end{array}$ \\
\hline 50 & 68.2645 & 53.5460 & $0.71 \%$ \\
\hline 100 & 111.1435 & 105.2376 & $1.05 \%$ \\
\hline 150 & 155.5959 & 157.8034 & $1.56 \%$ \\
\hline 200 & 206.6885 & 211.7917 & $2.36 \%$ \\
\hline 250 & 261.2662 & 261.7475 & $2.35 \%$ \\
\hline 300 & 315.1514 & 303.5567 & $0.71 \%$ \\
\hline 350 & 372.9918 & 361.5685 & $2.31 \%$ \\
\hline 400 & 415.6125 & 411.3163 & $2.26 \%$ \\
\hline 450 & 451.7615 & 456.4804 & $1.30 \%$ \\
\hline 500 & 511.9570 & 509.5114 & $1.90 \%$ \\
\hline
\end{tabular}

As with 4.2, linear fitting of calculated value is carried out. The empirical expression and the correlation factor are:

$$
\left\{\begin{array}{l}
y=0.9976 x+12.695 \\
R^{2}=0.9983
\end{array}\right.
$$

Formula (14) represents the measured value y (i.e., the fitted value) when the actual current is $\mathrm{x}$.

Table V and Fig. 9 show that calculated current based on voltage after the rectifier bridge and current before the rectifier bridge basically agrees with the actual primary side current, indicating that the theoretical formula is accurate.

The measured curve based on voltage after the rectifier bridge

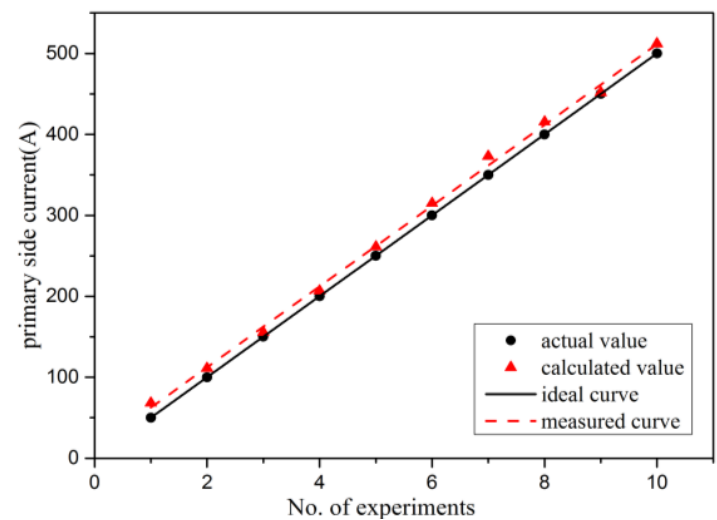

Fig. 9. The measured curve based on data after the rectifier bridge.

By contrast, the calculated result based on data after the rectifier bridge has larger error than that based on data before the rectifier bridge. This is because the voltage waveform after the rectifier bridge is viewed as the superposition of DC component $U_{d c}$ and the ideal sawtooth waveform $U_{b}$. In fact, voltage after the rectifier bridge has another component $\Delta U$ which is for compensating non-ideal voltage waveform. During the voltage transformation, $\Delta U$ also will provide some power frequency component before the rectifier bridge, which is neglected in the above calculation and causes a big error.

\section{Effect of Load Changes on Test Results}

The resistances after the rectifier bridge were set $100 \Omega$, $300 \Omega$ and $1000 \Omega$, while the primary side current chose $150 \mathrm{~A}, 300 \mathrm{~A}$ and $450 \mathrm{~A}$. Voltage and current waveforms before and after the rectifier bridge were calculated according to the above method. Results are shown in Table VI.

TABLE VI. CALCULATED RESULTS OF CURRENT UNDER LOAD CHANGES (UNIT: A).

\begin{tabular}{|c|c|c|c|c|c|c|}
\hline \multirow{2}{*}{$\begin{array}{c}\text { Actual } \\
\text { value }\end{array}$} & \multicolumn{3}{|c|}{$\begin{array}{c}\text { Calculated results based on } \\
\text { voltage before the rectifier } \\
\text { bridge }\end{array}$} & \multicolumn{2}{c|}{$\begin{array}{c}\text { Calculated results based on } \\
\text { voltage after the rectifier } \\
\text { bridge }\end{array}$} \\
\cline { 2 - 7 } & $\mathbf{1 0 0} \mathbf{\Omega}$ & $\mathbf{3 0 0} \mathbf{\Omega}$ & $\mathbf{1 0 0 0} \mathbf{\Omega}$ & $\mathbf{1 0 0} \mathbf{\Omega}$ & $\mathbf{3 0 0} \mathbf{\Omega}$ & $\mathbf{1 0 0 0} \mathbf{\Omega}$ \\
\hline 150 & 148.62 & 148.86 & 149.07 & 100.57 & 117.48 & 144.77 \\
\hline 300 & 297.18 & 302.40 & 303.65 & 254 & 288 & 310 \\
\hline 450 & 451.6 & 460 & 461 & 422 & 451 & 462.1 \\
\hline
\end{tabular}

Comparison of actual results using data before and after the rectifier bridge under load changes is shown in Fig. 10. On the whole, the calculated results based on voltage and current before the rectifier bridge are relatively ideal.

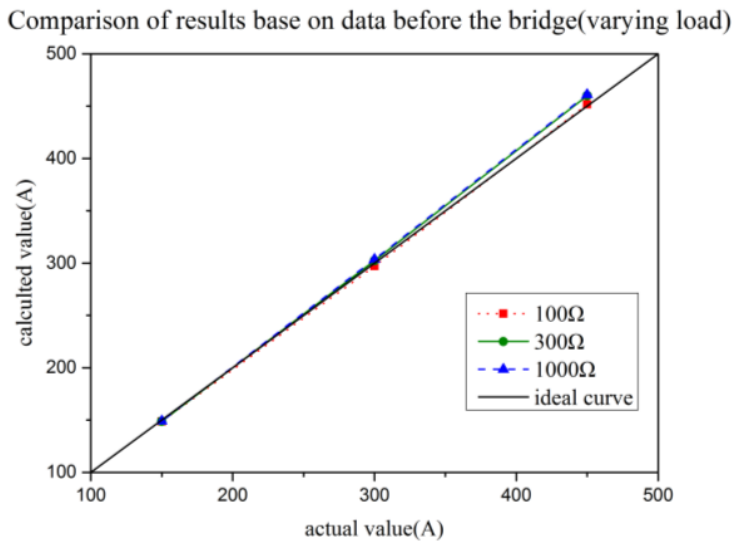

(a)

Comparison of results based on data after the bridge(varying load)

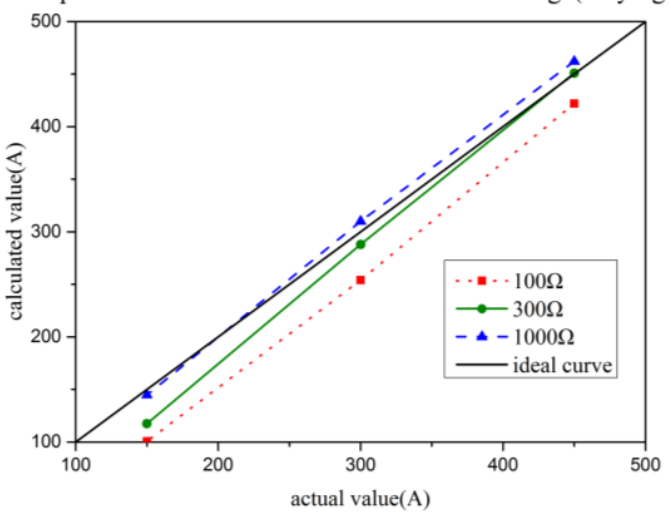

(b)

Fig. 10. Tested results under load changes: a) relation curve between actual results and calculated results based on data before the bridge (varying load); b) relation curve between actual results and calculated results based on data after the bridge (varying load).

Calculated results based on data before and after the rectifier bridge had small error under empty load or approximately empty load. With the increase of load power, 
calculated results based on data after the rectifier bridge will have a bigger error, which is related with to effect of load on the voltage waveform after the rectifier bridge. When the load resistance is small, the output waveform of the capacitance smoothing has a great impulse. Under this circumstance, the waveform cannot be viewed as the simple superposition of DC component and sawtooth waveform, but there is another voltage component for compensation $\Delta U$ that occupies a large proportion. However, $\Delta U$ is neglected in the calculation. Therefore, $\Delta U$ under larger load power will be bigger and the measuring error increases accordingly.

The calculated error based on data after the rectifier bridge is $5.6 \%$ when $100 \Omega$ load resistance is accessed to the $450 \mathrm{~A}$ primary side current. The load power at this moment was tested about $600 \mathrm{~mW}$. Load power of the sensor shall be controlled within a certain range in practical application, which not only can protect the sensor working in the maximum load capacity of the energy harvesting magnetic core, but also can decrease current measuring error.

\section{CONCLUSIONS}

A self-powered current measuring sensor is designed in this paper. Its functional framework and measuring principle are introduced, and its accuracy is verified by experiment. Based on the basic electromagnetic induction principle, this sensor uses existing energy harvesting magnetic core for current measurement, realizes synchronous measurement and power supply by one transformer. The current measuring device designed by using this sensor can meet the accuracy requirements and greatly reduce the cost. Such design has positive significance to the research and application of new online monitoring equipment.

The mathematical relationships between primary side current, secondary side voltage and current of the transformer are deduced. The primary side current is calculated according to the secondary side parameters, thus realizing the goal of current measurement. There's a rectification unit at the secondary side of the transformer. The calculation methods based on data before and after the rectifier bridge are discussed, respectively. Before the rectifier bridge, the voltage and current have same phase positions of the third harmonic before the rectifier bridge, when the current could be gained directly by calculating the power frequency component. After the rectifier bridge, the power frequency component of voltage before the rectifier bridge could be gained by calculating the non-power frequency component, which could be used to calculate the primary side current. Finally, measured results under varying load are analysed, which concludes that the measuring error under low $(<150 \mathrm{~mW})$ load power is relatively small $(<2.5 \%)$.

\section{REFERENCES}

[1] Wenxian Yang, R. Court, Jiesheng Jiang, "Research on a novel online condition monitoring technique for induction machinery", in 6th IET Int. Conf. Power Electronics, Machines and Drives (PEMD 2012), 2012, pp. P19-P19. DOI: 10.1049/cp.2012.0143.

[2] R. Mai, L. Fu, Xu HaiBo, "Dynamic line rating estimator with synchronized phasor measurement", in Int. Conf. Advanced Power System Automation and Protection, 2011, pp. 940-945. DOI: 10.1109/APAP.2011.6180545.

[3] M. Panteli, D. S. Kirschen, "Situation awareness in power systems: Theory, challenges and applications", Electric Power Systems Research, vol. 122, pp. 140-151, 2015. DOI: 10.1016/j.epsr.2015.01.008.

[4] Q. Yang, D. Xu, M. Li, "Development of an power transmission line online monitoring system", in 2011 Asia-Pacific Power and Energy Engineering Conf., 2011, pp. 1-5. DOI: 10.1109/APPEEC.2011.5748629.

[5] R. Moghe, F. Lambert, D. Divan, "A novel low-cost smart current sensor for utility conductors", IEEE Trans. Smart Grid, vol. 3, no. 2, pp. 653-663, 2012. DOI: 10.1109/TSG.2012.2185074.

[6] A. E. Emanuel, J. A. Orr, "Current harmonics measurement by means of current transformers", IEEE Trans. Power Delivery, vol. 22, no. 3, pp. 1318-1325, 2007. DOI: 10.1109/TPWRD.2007.900108.

[7] T.-Y. Zheng et al., "Development of a compensating algorithm for an iron-cored measurement current transformer", in 2009 IEEE Bucharest PowerTech, 2009, pp. 1-6. DOI: 10.1109/PTC.2009.5282027.

[8] W. F. Ray, C. R. Hewson, "High performance Rogowski current transducers", in Conf. Record 2000 IEEE Industry Applications Conf. Thirty-Fifth IAS Annual Meeting and World Conf. Industrial Applications of Electrical Energy, 2000, vol. 5, pp. 3083-3090. DOI: 10.1109/IAS.2000.882606

[9] K.-L. Chen, Y.-P. Tsai, N. Chen, "Design of a novel power current micro-sensor for traction power supply using two Hall ICs", in IEEE 70th Vehicular Technology Conf. Fall, 2009, pp. 1-5. DOI: 10.1109/VETECF.2009.5378777.

[10] W. C. Michie, A. Cruden, P. Niewczas, W. I. Madden, J. R. McDonald, M. Gauduin, "Harmonic analysis of current waveforms using optical current sensor", IEEE Trans. Instrumentation and Measurement, vol. 51, no. 5, pp. 1023-1026, 2002. DOI: 10.1109/TIM.2002.807802.

[11] Lin Du, Caisheng Wang, Xianzhi Li, Lijun Yang, Yan Mi, Caixin Sun, "A novel power supply of online monitoring systems for power transmission lines", IEEE Trans. Industrial Electronics, vol. 57, no. 8, pp. 2889-2895, 2010. DOI: 10.1109/TIE.2009.2037104.

[12] N. M. Roscoe, M. D. Judd, J. Fitch, "Development of magnetic induction energy harvesting for condition monitoring", IEEE Universities Power Engineering Conf., 2009, pp. 1-5.

[13] J. Ahola et al., "Design considerations for current transformer based energy harvesting for electronics attached to electric motor", in Int. Symposium on Power Electronics, Electrical Drives, Automation and Motion, 2008, pp. 901-905. DOI: 10.1109/SPEEDHAM.2008.4581191.

[14] N. Wang et al., "One-to-multipoint laser remote power supply system for wireless sensor networks", IEEE Sensors Journal, vol. 12, no. 2, pp. 389-396, 2012. DOI: 10.1109/JSEN.2011.2161465.

[15] D. Dondi, A. Bertacchini, D. Brunelli, L. Larcher, L. Benini, "Modeling and optimization of a solar energy harvester system for self-powered wireless sensor networks", IEEE Trans. Industrial Electronics, vol. 55, no. 7, pp. 2759-2766, 2008. DOI: 10.1109/TIE.2008.924449.

[16] Y. Liu et al., "A novel high-density power energy harvesting methodology for transmission line online monitoring devices", Review of Scientific Instruments, vol. 87, no. 7, 2016. DOI: 10.1063/1.4959556.

[17] T. Yue et al., "Power output characteristics of magnetic core in CT energy harvesting devices", High Voltage Apparatus, vol. 51, no. 1, pp. $18-23$ and 29, 2015.

[18] S. Chapman, Electric machinery fundamentals. Tata McGraw-Hill Education, 2005.

[19] Y. Liu et al., "Current transformer draw-out power supply design based on power-controlled method", Automation of Electric Power Systems, vol. 34, no. 3, pp. 70-74, 2010. 